\title{
Need for recovery from work in relation to age: a prospective cohort study
}

\author{
D. C. L. Mohren • N. W. H. Jansen • \\ IJ. Kant
}

Received: 16 June 2009/ Accepted: 12 November 2009/Published online: 4 December 2009

(c) The Author(s) 2009. This article is published with open access at Springerlink.com

\begin{abstract}
Purpose To investigate the impact of increasing age on the need for recovery (NFR) over time among day workers Methods The study is based on data from the first 2 years of follow-up of the Maastricht Cohort Study $(n=7,734)$. To investigate whether age predicted the onset of elevated NFR, multivariate survival analyses were conducted Results The highest levels of NFR were observed in the age group of 46-55 years. The relative risk for developing elevated NFR was highest in the age groups 36-45 years (RR $1.30 ; 1.07-1.58)$ and 46-55 years (RR 1.25 ; $1.03-$ 1.52 ) in men and 46-55 years (RR $1.36 ; 1.04-1.77)$ in women when compared to the reference group

Conclusions While NFR increased with age until the age of 55, this was followed by decreased levels of NFR among older employees. Explanations for the decreasing levels of NFR in the highest age group can be found in several domains such as the work environment, private situation and compensation strategies.
\end{abstract}

Keywords Need for recovery - Ageing ·

Working population $\cdot$ Epidemiology

\section{Introduction}

Retirement and age at retirement have been the subject of many political, social and medical discussions over the years. The increase in the population of ageing people in

D. C. L. Mohren $(\square) \cdot$ N. W. H. Jansen · IJ. Kant CAPHRI School for Public Health and Primary Care, Department of Epidemiology, Maastricht University, P.O. Box 616, 6200 MD Maastricht, The Netherlands

e-mail: DCL.Mohren@epid.unimaas.nl developed countries has motivated national governments as well as the European Union to develop policies for encouraging the labour force participation of older workers and eliminating mandatory retirement (Cooke 2006). The trend towards earlier retirement has reversed, and growing numbers of employees are planning to work longer. In industrialized countries, the population above 50 years of age will grow considerably in the next years (Costa and Sartori 2007). For example in The Netherlands, the gross labour participating of older people (55-64 years) nearly doubled between 1996 and the first half of 2007, to more than 47\% (Statistics Netherlands 2007).

The definition of an ageing worker is generally based on the period when major changes occur in relevant workrelated functions during the course of work life. All people age chronologically at the same speed, but the way in which people physically age depends on their genetics, health habits, illnesses, environment and their occupation (Naumanen 2006). In general, functional capacities, mainly physical, show a declining trend after the age of 30 , and the trend can become critical after the next 15-20 years if the physical demands of work do not decline (Ilmarinen 2001). These declines are primarily associated with reductions in cardiovascular, respiratory, metabolic and muscular functions. Declining functional capacities may affect individuals' ability to perform the tasks that their jobs demand. Workers may find themselves working closer to their maximal capacities, putting themselves at greater risk for chronic fatigue or musculoskeletal injuries (Kenny et al. 2008). Apart from changes in physical capacities of the ageing worker, also changes in mental functioning are reported in the literature. The most important changes in mental functions are related to the weakening of precision and the speed of perception (Ilmarinen 2001). On the other hand, some mental characteristics can also strengthen with 
age, such as the ability to deliberate and reason (Baltes and Smith 1990; Schaie 1994). Although the group of ageing workers has attracted substantial research interest, so far their health and well-being have not been studied extensively; and therefore, the actual health implications of longer working careers remain unclear.

The concept of need for recovery from work could be considered an important perspective to study health effects of working at an older age. Need for recovery represents short-term effects of a day of work (Sluiter et al. 2001) and was defined as the need to recuperate from work-induced fatigue, primarily experienced after a day of work (Jansen et al. 2002). Need for recovery can be observed especially during the last hours of work and immediately after work. It is characterized by temporary feelings of overload, irritability, social withdrawal, lack of energy for new effort and reduced performance (Van Veldhoven 2008). Need for recovery from work can be recognized in the off-work situation by feelings of 'wanting to be left alone for a while' or 'having to lie-down for a while' (Sluiter et al. 2001). Repeated insufficient recovery from work-induced fatigue is seen as the start of a vicious circle where extra effort has to be exerted at the beginning of every new working period to rebalance the suboptimal psycho-physiological state and to prevent performance breakdown (Sluiter et al. 1999). Repeated insufficient recovery from work is related to health problems (Meijman 1989; Van der Beek et al. 1995). A study among truck drivers has shown that high need for recovery was prospectively related to increased sickness absence (de Croon et al. 2003). Furthermore, employees with high need for recovery are reported to have an increased risk of subsequent cardiovascular disease (Van Amelsvoort et al. 2003).

It is hypothesized that the decrease of work capacity of the ageing worker will result in increasing need for recovery levels if the workload remains the same. As such need for recovery might be considered an instrument to assess potential imbalance between demands of work and the functional capacities of the ageing worker. So far, only few studies have reported on the association between age and need for recovery. Sluiter et al. (Sluiter et al. 2001) observed that age was not significant in the prediction of need for recovery. A study by Jansen et al. (2002) showed that employees aged 46-55 scored somewhat higher on need for recovery compared to employees aged 36-45. Kiss et al. (2008) observed significantly higher mean recovery scores in older workers ( $\geq 45$ years) when compared to younger workers ( $<45$ years). Whereas crosssectional studies gain insight into the magnitude of the problem at a specific point in time, and may reveal associations between work demands, age and need for recovery, longitudinal studies are necessary to investigate the net-effect of age on need for recovery. To date, we are not aware of studies investigating the longitudinal relationship between age (categories) and need for recovery from work.

When studying the relationship between age and need for recovery over time various factors should be taken into account, such as demographics, work environment, health, lifestyle and characteristics of the private situation. Some studies have found gender differences in the need for recovery, with men reporting higher levels of need for recovery when compared to women (Jansen et al. 2002). Also differences in need for recovery are observed when comparing different educational levels, with employees with a lower educational level reporting higher need for recovery scores (Jansen et al. 2002). High psychological job demands, low decision latitude, physically demanding work and work-family conflict have been found to be associated with elevated need for recovery (Jansen et al. 2002, 2003a; Eriksen et al. 2006). Need for recovery further substantially varies when different working hours, patterns or schedules are considered (Jansen et al. 2003b; De Raeve et al. 2007). Therefore, in this study, need for recovery will be studied in day workers exclusively.

The aim of the present prospective study was to investigate whether increasing age is related to higher need for recovery from work over time, while taking into account demographic, work-related factors and characteristics of the private situation.

\section{Methods}

Sampling and procedures

The present study is based on data of the first six questionnaires of the Maastricht Cohort Study on "Fatigue at Work" (Kant et al. 2003), that is, a total follow-up of 2 years. Employees were followed by means of selfadministered questionnaires, which they received every 4 months. Once a year, employees received an extensive questionnaire with items on work-related factors, demographics, nonwork-related factors and health factors. Twice a year, employees received a short questionnaire, capturing mainly outcome measures. In May 1998, a total of 26,978 employees from 45 companies and organizations received a letter at home, inviting participation and the selfadministered baseline questionnaire. A reminder was sent out after 2 weeks. After 6 weeks, a brief nonresponse questionnaire was sent to a random subsample of 600 nonrespondents. Nonresponse analyses yielded no significant differences between respondents and nonrespondents regarding demographic characteristics. Nonrespondents were somewhat less likely to report difficulties in work execution, fatigue complaints and sick leave (Kant et al. 2003). Altogether, 12,161 employees completed and 
returned the baseline questionnaire (response rate of $45 \%$ ). Sixty-six questionnaires were excluded from analysis due to technical reasons or because inclusion criteria were not met. Included were employees aged 18-65. Written consent was obtained from all participants. The study was of a strict observational nature and was conducted in accordance with the ethical standards laid down in the 1964 Declaration of Helsinki. The baseline (T0) cohort consists of $8,840(73 \%)$ men and 3,255 (27\%) women. All employees who returned the baseline questionnaire (T0) received the two short questionnaires $\mathrm{T} 1$ in September 1998 (response rate $87.6 \%, n=10,592$ ) and T2 in January 1999 (response rate 84.9\%, $n=10,270$ ) as well. Employees returning the baseline questionnaire and at least one of the short questionnaires ( $\mathrm{T} 1$ and/or $\mathrm{T} 2$ ) received the extensive questionnaire T3 in May 1999 (response rate $79.8 \%, n=9,655)$. Employees returning the T3 questionnaire also received the short questionnaires $\mathrm{T} 4$ in September 1999 (response rate $74.0 \%, n=8,956$ ) and $\mathrm{T} 5$ in January 2000 (response rate 71.9\%, $n=8,692$ ). Employees who returned the questionnaire at $\mathrm{T} 3$ and at least one of the consecutive short questionnaires (T4 and/or T5) also received the extensive questionnaire T6 in May 2000 (response rate $66.7 \%, n=8,070$ ). Further information about the procedure and baseline characteristics has been reported elsewhere (Kant et al. 2003).

For describing associations between characteristics of the study population and need for recovery from work, we used the baseline questionnaire (T0, May 1998). Excluded were those employees who were absent from work at the time of completing the questionnaire and those involved in shift work, resulting in a study population of $\boldsymbol{n}=7,734$, of which 5,586 were men, and 2,148 were women, for the cross-sectional analyses. For the prospective analyses over 2 years of follow-up, we additionally excluded prevalent cases of need for recovery at baseline, resulting in a study population of $\boldsymbol{n}=5,990$, of which 4,254 were men, and 1,736 were women.

\section{Measures}

\section{Need for recovery from work}

Need for recovery from work was assessed with a scale from the Dutch Questionnaire on the Experience and Evaluation of Work (VBBA; Van Veldhoven and Broersen 2003). The scale contains 11 dichotomous items, representing short-term effects of a day of work. All items were recoded in such a way that higher scores indicate "more complaints', i.e. a higher need for recovery. The recoded scores are presented in a range from 0 to 100 . The Cronbach's alpha of the scale is 0.78 (Jansen et al. 2002). Examples of items in the scale are 'I find it hard to relax at the end of a working day' and 'Because of my job, at the end of the working day, I feel rather exhausted' (Van Veldhoven and Broersen 2003). In the present study, the upper quartile was used to define a contrast between employees with a high versus low-medium need for recovery, which corresponds with a cut-off point of 6 on the 11-item scale as recommended by Broersen et al. (Broersen et al. 2004). The level of need for recovery was determined in each questionnaire (T0, T1, T2, T3, T4, T5, T6).

\section{Demographic and health factors}

Employees provided information on gender, age, educational level and the presence of a long-term illness through self-report in the questionnaires. Employees were divided into five age groups, that is, $18-25,26-35,36-45,46-55$ and 56-65 years. Smoking status was assessed by a single dichotomous item ("Do you smoke every day?").

\section{Characteristics of the private situation}

Living situation was operationalized as living alone (yes/ no). Work-family conflict was measured by one dichotomous item asking employees whether they were able to adequately combine work and family life.

\section{Work characteristics}

Regarding working hours, employees were amongst others asked for their working hours per week, categorized as $>40,36-40,26-35,16-25$ and $<16 \mathrm{~h}$ per week. Also, information on overtime was collected using an item on frequent overtime (yes/no). A Dutch version of the Job Content Questionnaire was used to measure psychological job demands and decision latitude (Karasek 1985). Psychological job demands were assessed by the sum of five items (Chronbach's alpha 0.69). Decision latitude (Chronbach's alpha 0.81) was measured by the sum of two subscales: skill discretion and decision authority. The response options varied from "strongly disagree" to "strongly agree" on a four-point scale. The total score was then divided into tertiles, resulting in low, medium and high levels of psychological job demands or decision latitude. To assess whether employees perceived their work as physically demanding, one item of the Dutch questionnaire on Work and Health (VAG; Gründemann et al. 1993) was used.

Statistical analysis

Because the distribution of need for recovery was skewed to the left, Poisson regression analyses were conducted to 
test differences in mean levels of need for recovery in the cross-sectional analyses. To test differences in the percentage of elevated need for recovery (scoring above the upper quartile), chi-square tests were conducted in the cross-sectional analyses. These cross-sectional analyses were based on the baseline measurement (T0) and concern crude analyses with an explorative character.

To investigate whether age predicted the onset of elevated need for recovery, multivariate survival analyses using Cox regression were conducted, in which we modelled the time to first 'need for recovery caseness' at T1, $\mathrm{T} 2, \mathrm{~T} 3, \mathrm{~T} 4, \mathrm{~T} 5$ or T6. Relative risks (RRs) and 95\% confidence intervals $(95 \% \mathrm{CI})$ were calculated for need for recovery adjusted for educational level and smoking in the first step. In the second step, we additionally adjusted the RRs for the presence of a long-term illness. In the third step, we additionally adjusted the RRs for working hours per week, overtime work, psychological job demands, decision latitude and physically demanding work. Finally, in the fourth step, the RRs were additionally adjusted for work-family conflict and living situation. In all analyses, differences were considered to be statistically significant at $p<0.05$. Data were analysed using SPSS version 15.0 and SAS version 9.1.

\section{Results}

Table 1 shows the point prevalences of demographic, work and health characteristics of the baseline study population stratified for age, revealing relevant differences between the five age groups. The highest percentage of female employees, those living alone, and having physically demanding work, was found in the age group 18-25 years. The highest percentage of employees with a low educational level, and low levels of decision latitude were found in the oldest age group. In the age group of 46-55 years, the highest percentage of long-term illness and smoking was reported. Employees between 36 and 45 years of age reported the highest percentage of work-family conflict, working overtime, and high psychological job demands.

As listed in Table 2, the overall mean score for need for recovery in our study population was $35.97(\mathrm{SD}=25.97)$ at baseline. Over $22 \%$ of the employees reported a need for recovery score above the cut-off point. With regard to the different age groups, the following pattern was observed at baseline measurement: need for recovery was lowest in the lowest age group and increased with increasing age until the age group 46-55 years, and then decreased in the age group of 56-65 years. Male employees reported a higher need for recovery compared to female employees. Also, in the different age groups, differences in need for recovery were observed with respect to gender, with statistically significant differences found for the age groups of 2635 years and 36-45 years. Substantial and statistical significant differences in need for recovery were observed in the different age groups $(p<0.0001)$ across demographic, health, domestic and work-related characteristics. The highest percentage of need for recovery cases was found among those employees between 46 and 55 years of age. In all age groups, reporting work-family conflict, psychological job demands, overtime work and physically demanding work were associated with significantly higher levels of need for recovery.

Also, having a long-term illness and working hours per week were associated with significantly higher levels of need for recovery in every age group, except for the youngest (18-25 years).

Living alone was associated with significantly higher levels of need for recovery in the oldest age groups (46-55, 56-65 years). Low decision latitude was associated with significantly higher levels of need for recovery in the 3645 and 46-55 age groups. Smoking was significantly associated with higher levels of need for recovery in almost all age groups.

In Table 3, the relationship between age and future need for recovery caseness is given. When age was operationalized as a continuous variable (10 years increase), no significant relation was found with need for recovery caseness over time. When considering age as a categorical variable, more detailed information was obtained. For men, the age groups $36-45$ and $46-55$ years were statistically significant associated with elevated need for recovery over time ((RR 1.30; 95\% CI 1.07-1.58) and (RR 1.25; 95\% CI $1.03-1.52)$, respectively)) when compared to the age group of 26-35 years, when adjusting for educational level and smoking. After additionally correcting in several steps for long-term illness, working hours per week, overtime work, psychological job demands, decision latitude, physical demanding work, work-family conflict and living situation, the effects remained significant in both age groups. In both the older (56-65 years) and the younger (18-25 years) employees, no effect was found when compared to the reference age group. Among women, a significant effect was found in the age group of 46-55 years compared with the age group of 26-35 years. After correcting for longterm illness, working hours per week, overtime work, psychological job demands, decision latitude, physically demanding work, work-family conflict and living situation, no significant effects remained.

\section{Discussion}

The objective of this study was to investigate the impact of increasing age on the need for recovery over time, while 
Table 1 Descriptive characteristics of the study population at baseline measurement (May 1998) according to age group

\begin{tabular}{|c|c|c|c|c|c|c|c|}
\hline $\begin{array}{l}\text { Age } \\
\text { groups }\end{array}$ & $\begin{array}{l}\text { Total population } \\
(n=7,734)\end{array}$ & $\begin{array}{l}18-25 \text { years } \\
(n=187)\end{array}$ & $\begin{array}{l}26-35 \text { years } \\
(n=1,665)\end{array}$ & $\begin{array}{l}36-45 \text { years } \\
(n=2,925)\end{array}$ & $\begin{array}{l}46-55 \text { years } \\
(n=2,548)\end{array}$ & $\begin{array}{l}56-65 \text { years } \\
(n=409)\end{array}$ & $p$ value \\
\hline \multicolumn{8}{|c|}{ Gender $(\%)$} \\
\hline Male & 72.2 & 48.1 & 56.6 & 71.5 & 83.0 & 85.1 & \multirow[t]{2}{*}{$<0.0001$} \\
\hline Female & 27.8 & 51.9 & 43.4 & 28.5 & 17.0 & 14.9 & \\
\hline \multicolumn{8}{|c|}{ Educational level (\%) } \\
\hline Low & 22.9 & 9.6 & 13.2 & 21.2 & 30.3 & 35.2 & \multirow[t]{3}{*}{$<0.0001$} \\
\hline Medium & 30.1 & 38.5 & 33.2 & 30.7 & 27.5 & 25.4 & \\
\hline High & 47 & 51.9 & 53.6 & 48.1 & 42.1 & 39.4 & \\
\hline \multicolumn{8}{|c|}{ Long-term illness (\%) } \\
\hline Yes & 21.5 & 12.8 & 15.9 & 19.2 & 27.8 & 25.5 & \multirow[t]{2}{*}{$<0.0001$} \\
\hline No & 78.5 & 87.2 & 84.1 & 80.8 & 72.2 & 74.5 & \\
\hline \multicolumn{8}{|c|}{ Living situation alone (\%) } \\
\hline Yes & 10.3 & 18.8 & 14.4 & 9.3 & 8.2 & 9.5 & \multirow[t]{2}{*}{$<0.0001$} \\
\hline No & 89.7 & 81.2 & 85.6 & 90.7 & 91.8 & 90.5 & \\
\hline \multicolumn{8}{|c|}{ Work-family conflict (\%) } \\
\hline Yes & 8.4 & 7.1 & 9.1 & 9.9 & 6.7 & 5.7 & \multirow[t]{2}{*}{$<0.0001$} \\
\hline No & 91.6 & 92.9 & 90.9 & 90.1 & 93.3 & 94.3 & \\
\hline \multicolumn{8}{|c|}{ Working hours per week (\%) } \\
\hline$>40$ & 25.6 & 16.7 & 21.8 & 24.3 & 30.2 & 25.8 & \multirow[t]{5}{*}{$<0.0001$} \\
\hline $36-40$ & 54.6 & 65.1 & 53.7 & 53.5 & 55.6 & 54.1 & \\
\hline $26-35$ & 8.1 & 9.1 & 8.6 & 9.4 & 6.3 & 7.9 & \\
\hline $16-25$ & 10.3 & 7 & 14.5 & 11.5 & 6.6 & 9.8 & \\
\hline$<16$ & 1.4 & 2.2 & 1.4 & 1.3 & 1.3 & 2.5 & \\
\hline \multicolumn{8}{|c|}{ Overtime $(\%)$} \\
\hline Yes & 50.7 & 46.5 & 52.1 & 53.7 & 48.9 & 37.1 & \multirow[t]{2}{*}{$<0.0001$} \\
\hline No & 49.3 & 53.5 & 47.9 & 46.3 & 51.1 & 62.9 & \\
\hline \multicolumn{8}{|c|}{ Psychological job demands (\%) } \\
\hline Low & 31.8 & 44.9 & 37.3 & 28.2 & 30.2 & 38.6 & \multirow[t]{3}{*}{$<0.0001$} \\
\hline Medium & 33.3 & 33.1 & 32.2 & 34.4 & 32.7 & 33.1 & \\
\hline High & 35 & 21.9 & 30.5 & 37.4 & 37.1 & 28.3 & \\
\hline \multicolumn{8}{|c|}{ Decision latitude (\%) } \\
\hline Low & 28.3 & 29.3 & 29.4 & 27.3 & 28.4 & 30.6 & \multirow[t]{3}{*}{0.556} \\
\hline Medium & 34.7 & 37 & 33.3 & 35.1 & 34.9 & 36.3 & \\
\hline High & 36.9 & 33.7 & 37.4 & 37.6 & 36.7 & 33.1 & \\
\hline \multicolumn{8}{|c|}{ Physically demanding work (\%) } \\
\hline Yes & 14.7 & 20.8 & 15.9 & 13.3 & 15.2 & 13.8 & \multirow[t]{2}{*}{0.013} \\
\hline No & 85.3 & 79.2 & 84.1 & 86.7 & 84.8 & 86.2 & \\
\hline \multicolumn{8}{|c|}{ Smoking (\%) } \\
\hline Yes & 23 & 13.4 & 17.3 & 24.8 & 25.1 & 24.9 & \multirow[t]{2}{*}{$<0.0001$} \\
\hline No & 77 & 86.6 & 82.7 & 75.2 & 74.9 & 75.1 & \\
\hline
\end{tabular}

taking relevant confounding factors into account. With regard to the representativeness of our study for the general working population, it should be noted that we excluded shift workers, and therefore the results of this study are only applicable to day workers. The reason for excluding shift workers was that the relationship between age and need for recovery may be distorted by the specific work schedule the employee is involved in, because in general shift workers report higher need for recovery levels compared to day workers (Jansen et al. 2003b).

In the cross-sectional analyses, the highest levels of need for recovery and the highest proportion of cases of need for recovery were observed in the age group of 4655 years. In the longitudinal analyses, the relative risk for 


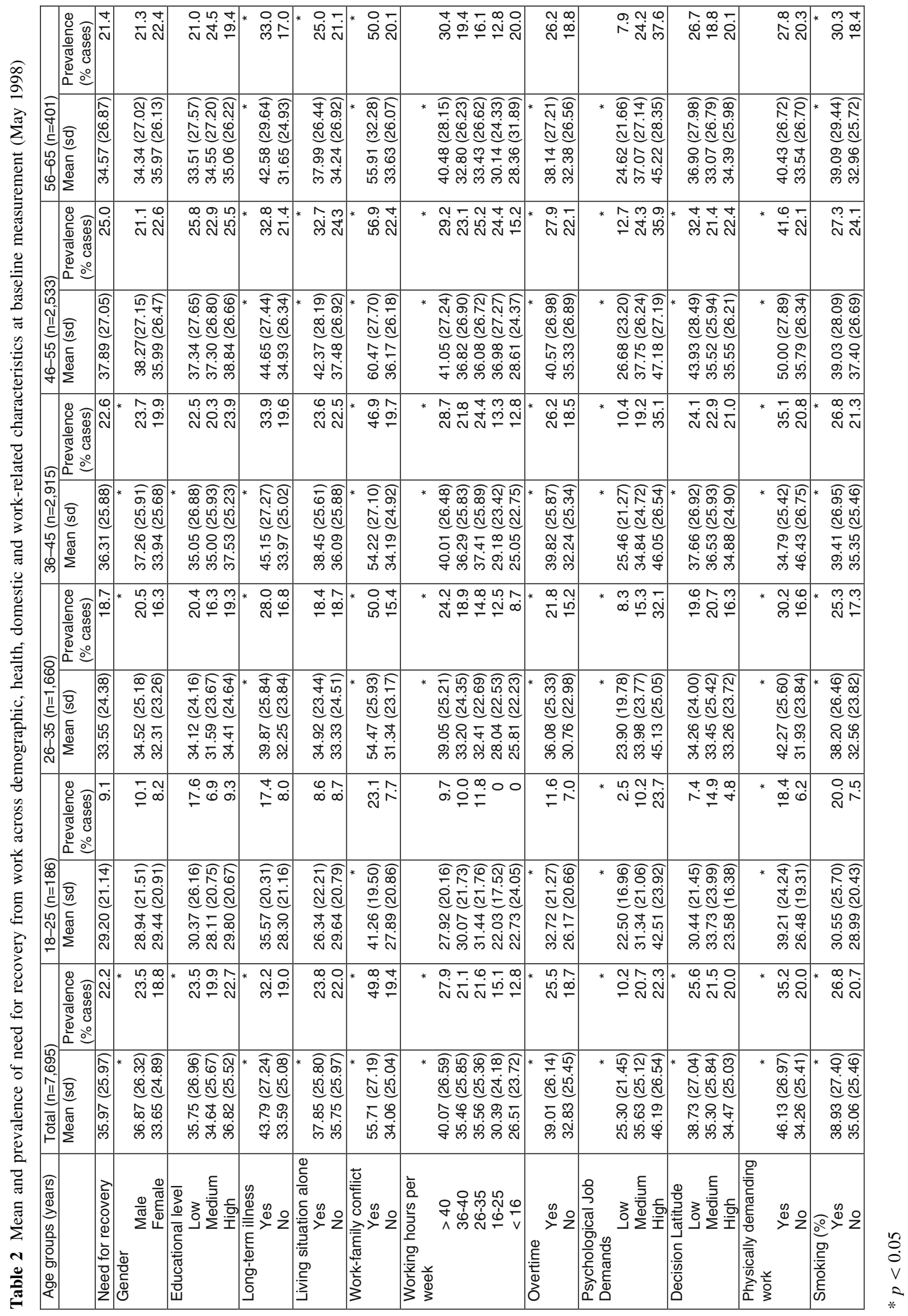


Table 3 Age as a risk factor for high need for recovery over time

\begin{tabular}{|c|c|c|c|c|}
\hline & $\mathrm{RR}^{\mathrm{a}}(95 \% \mathrm{CI})$ & $\mathrm{RR}^{\mathrm{b}}(95 \% \mathrm{CI})$ & $\mathrm{RR}^{\mathrm{c}}(95 \% \mathrm{CI})$ & $\mathrm{RR}^{\mathrm{d}}(95 \% \mathrm{CI})$ \\
\hline \multicolumn{5}{|l|}{ Men } \\
\hline Age (10 years increase) & $1.04(0.96-1.13)$ & $1.02(0.94-1.10)$ & $1.03(0.95-1.11)$ & $1.05(0.97-1.14)$ \\
\hline \multicolumn{5}{|l|}{ Age (years) } \\
\hline $18-25$ & $1.01(0.59-1.72)$ & $0.98(0.58-1.67)$ & $1.12(0.66-1.92)$ & $1.11(0.65-1.89)$ \\
\hline 26-35 (ref) & 1 & 1 & 1 & 1 \\
\hline $36-45$ & $1.30(1.07-1.58)$ & $1.29(1.06-1.56)$ & $1.24(1.02-1.51)$ & $1.24(1.03-1.51)$ \\
\hline $46-55$ & $1.25(1.03-1.52)$ & $1.20(0.99-1.46)$ & $1.21(0.99-1.47)$ & $1.24(1.02-1.51)$ \\
\hline $56-65$ & $0.87(0.62-1.21)$ & $0.84(0.60-1.17)$ & $0.88(0.63-1.28)$ & $0.91(0.65-1.28)$ \\
\hline \multicolumn{5}{|l|}{ Women } \\
\hline Age (10 years increase) & $1.12(0.99-1.26)$ & $1.09(0.97-1.23)$ & $1.06(0.94-1.19)$ & $1.05(0.93-1.18)$ \\
\hline \multicolumn{5}{|l|}{ Age (years) } \\
\hline $18-25$ & $0.86(0.54-1.36)$ & $0.88(0.55-1.41)$ & $0.91(0.57-1.46)$ & $0.93(0.58-1.49)$ \\
\hline 26-35 (ref) & 1 & 1 & 1 & 1 \\
\hline $36-45$ & $1.00(0.80-1.24)$ & $0.99(0.80-1.23)$ & $0.96(0.77-1.19)$ & $0.93(0.74-1.16)$ \\
\hline $46-55$ & $1.36(1.04-1.77)$ & $1.28(0.98-1.68)$ & $1.20(0.92-1.57)$ & $1.22(0.93-1.59)$ \\
\hline $56-65$ & $0.96(0.50-1.83)$ & $0.90(0.47-1.71)$ & $0.87(0.46-1.67)$ & $0.85(0.44-1.62)$ \\
\hline
\end{tabular}

developing elevated need for recovery from work was highest in the age groups 36-45 and 46-55 years in men and 46-55 years in women when compared to the reference group of 26-35 years. While we expected a rather linear association between increasing age and need for recovery over time, we however observed decreasing levels of need for recovery in the highest age group (5665 years). These findings are in accordance with the study by Kiss et al. (2008), where the highest level of need for recovery was found in the age group of 50-54 years with a decrease in need for recovery after 55 years. Probably, this is also the explanation for a nonsignificant effect on need for recovery when age was considered as a continuous variable in the analyses. Since the relationship between age and need for recovery is nonlinear, it is informative to study age categories which better correspond to a specific point in the working career. Furthermore, also from an occupational health perspective, it is very valuable to distinguish important age subgroups in the working population who may encounter different need for recovery levels.

Explanations for the decreasing levels of need for recovery in the highest age group can be found in several domains. First, in the work environment, the process of downshifting may have been initiated, in terms of reduction in working hours in the job, less overwork or in terms of leaving the workforce. An indication for this reasoning can be found in Table 1, where for instance, the prevalence of overtime work was lowest in the highest age group.
Additionally, those workers with health complaints may have already left the labour force or have adapted to health problems by reducing working hours or changing jobs for example (De Raeve et al. 2009), leaving healthy workers in this high age group. In The Netherlands in 1995, the net labour force participation in the age group 25-50 years was $71.3 \%$ in contrast to $38.5 \%$ in the age group 50-65 years (Statistics Netherlands 2008), which supports the downshifting process. Although we found a lower percentage of overwork in the highest age group, in accordance with the findings of Van der Hulst et al. (2006), Kalwij and Vermeulen (2008) found in a cross-sectional study no evidence for diminishing working hours with age. On the other hand, they stated that convincing evidence could only be obtained by longitudinal data where labour supply transitions of the same individuals are observed.

Second, also differences in the private situation may account for varying levels of need for recovery. For example, the proportion of work-family conflict was highest in the age group 36-45 years. Work-family conflict can be considered a strong risk factor for elevated need for recovery (Jansen et al. 2003a). Third, older employees may have developed more compensation strategies for dealing with need for recovery at the end of the day, due to strategies and skills related to their experience and expertise in the working career (Silverstein 2008). Also, Baltes and Carstensen (1996) suggest that employees may be better in maintaining and improving their psychological 
well-being in later life due to better coping methods or better work adjustment.

In this study, a broad range of potentially confounding variables was carefully considered, but the effect was limited. Since these potential confounders originated from the domains demographics, health, work environment and private situation, the scope for a major impact of residual confounding is probably limited.

In the prospective analyses, only incident need for recovery caseness was studied. By excluding prevalent cases of need for recovery at baseline for the prospective analyses, we have lost a specific group of employees with already an elevated need for recovery. For future studies, it might be valuable to examine whether these elevated levels of need for recovery differentially increase or decrease in the different age groups. On the other hand, an important limitation of earlier studies is that they are mostly based on cross-sectional designs, meaning that they cannot examine age differences in the development of health problems among employees across time.

Another important point to discuss is the effect of the healthy worker on the results. As described in the method section, the response at baseline was $45 \%$. A nonresponse analysis at baseline revealed lower well-being among the respondents (e.g. higher percentage reporting fatigue complaints, difficulties in work execution because of health complaints and sickness absence when compared to nonrespondents). On the other hand, nonresponse analysis after 1-year follow-up showed that nonrespondents during the first year of follow-up were likely to report more fatigue complaints at baseline than respondents. Furthermore, differences were found with regard to demographic and health complaints (Kant et al. 2003). So, at the start of our study, respondents were less healthy, and during follow-up, they were healthier when compared to those dropping out of the study. Also, Table 1 shows indications of a possible healthy worker effect. Employees in the highest age group showed a lower percentage of long-term illnesses when compared to the age group of 46-55 years. One may carefully conclude that this oldest group is slightly healthier as a result of a drop-out of those employees who are chronically ill.

This study showed that age is related to different levels of need for recovery over time. If high need for recovery is present for a prolonged period of time, this can be considered an indicator of failing recovery that might have substantial individual health consequences (Van Veldhoven 2008), such as sickness absence (de Croon et al. 2003) and an increased risk of subsequent cardiovascular disease (Van Amelsvoort et al. 2003). Work performance and safety behaviour at work may also be compromised (Van Veldhoven 2008). Swaen et al. (2003) for instance showed that need for recovery was an independent risk factor for being injured in an occupational accident. Finally, in a study by De Raeve et al. (2009), it was shown that internal job mobility was significantly predicted by increased levels of need for recovery.

While need for recovery increased with age until the age of 55, this was followed by decreased need for recovery levels among older employees. As stated earlier, this may be partly explained by the process of downshifting in this group. Current trends in society towards higher labour force participation and later retirement may however compromise the possibilities for downshifting at a higher age in the future, and thereby change the relationship between age and need for recovery. The efforts of the Dutch government to try to turn round the trends towards a lower participation and lower early retirement age seem to be successful by now. Since 1995, employment rates of older workers are gradually increasing. Male employment rates in age group 55-59 years for instance decreased from 1971 to 1995 from 87 to $58 \%$ but increased since then to $76 \%$ in 2005. Female employment rates particularly increased tremendously at ages above 50 (Ekamper 2006). Therefore, it is expected that higher levels of need for recovery will also be observed in the highest age group of workers in the near future. This may be due to the fact that a longer working career becomes more imperative for the future working population. Therefore, to assess the impact of this imperative trend, a follow-up of this study will be worthwhile in the upcoming years.

Acknowledgments Conflict of interest The authors declare that they have no conflict of interest.

Open Access This article is distributed under the terms of the Creative Commons Attribution Noncommercial License which permits any noncommercial use, distribution, and reproduction in any medium, provided the original author(s) and source are credited.

\section{References}

Baltes MM, Carstensen LL (1996) The process of succesful ageing. Ageing Soc 16:397-422

Baltes PB, Smith J (1990) Toward a psychology of wisdom. In: Stenberg RJ (ed) Wisdom: its nature, origin and development. Cambridge University Press, New York

Broersen JPJ, Fortuin RJ, Dijkstra M, Van Veldhoven M, Prins J (2004) Monitor Arboconvenanten: kengetallen en grenswaarden [Monitor working conditions agreements: indicators and cutoffs]. TBV 12:100-104

Cooke M (2006) Policy changes and the labour force participation of older workers: evidence from six countries. Can J Aging 25:387400

Costa G, Sartori S (2007) Ageing, working hours and work ability. Ergonomics 50:1914-1930

de Croon EM, Sluiter JK, Frings-Dresen MH (2003) Need for recovery after work predicts sickness absence: a 2-year prospective cohort study in truck drivers. J Psychosom Res 55:331-339 
De Raeve L, Jansen NW, Kant IJ (2007) Health effects of transitions in work schedule, workhours and overtime in a prospective cohort study. Scand J Work Environ Health 33:105-113

De Raeve L, Kant IJ, Jansen NWH, Vasse RM, Van den Brandt PA (2009) Changes in mental health as a predictor of changes in working time arrangements and occupational mobility: results from a prospective cohort study. J Psychosom Res 66:137-145

Ekamper P (2006) Ageing of the labor market in The Netherlands: an overview. In: Rocco TS, Thijssen JGL (eds) Older workers, new directions; employment and development in an ageing labor market. Center for Labor Research and Studies, Florida International University, Miami

Eriksen HR, Ihlebaek C, Jansen JP, Burdorf A (2006) The relations between psychosocial factors at work and health status among workers in home care organizations. Int J Behav Med 13:183192

Gründemann RWM, Smulders PWG, De Winter CR (1993) Handleiding Vragenlijst Arbeid en Gezondheid [Manual, Questionnaire on work and health]. Swets \& Zeitlinger, Lisse

Ilmarinen JE (2001) Aging workers. Occup Environ Med 58:546-552

Jansen NWH, Kant IJ, Van den Brandt PA (2002) Need for recovery in the working population: description and associations with fatigue and psychological distress. Int J Behav Med 9:322-340

Jansen NWH, Kant IJ, Kristensen TS, Nijhuis FJN (2003a) Antecedents and consequences of work-family conflict: a prospective cohort study. J Occup Environ Med 45:479-491

Jansen NWH, Kant IJ, Van Amelsvoort LPGM, Nijhuis FJN, Van den Brandt PA (2003b) Need for recovery from work: evaluating short-term effects of working hours, patterns and schedules. Ergonomics 46:664-680

Kalwij A, Vermeulen F (2008) Health and labour force participation of older people in Europe: what do objective health indicators add to the analysis? Health Econ 17:619-638

Kant IJ, Bültmann U, Schröer CAP, Beurskens AJHM, Van Amelsvoort LPGM, Swaen GMH (2003) An epidemiological approach to study fatigue in the working population: the Maastricht Cohort Study. Occup Environ Med 60(Suppl 1):i32-i39

Karasek RA (1985) The job content Questionnaire and user's Guide (version 1.1). Department of Industrial and Systems Engineering, University of Southern California, Los Angeles

Kenny GP, Yardley JE, Martineau L, Jay O (2008) Physical work capacity in older adults: implications for the aging worker. Am J Ind Med 51:610-625

Kiss P, De Meester M, Braeckman L (2008) Differences between younger and older workers in the need for recovery after work. Int Arch Occup Environ Health 81:311-320

Meijman T (1989) Mentale belasting en werkstress. Een arbeidspsychologische benadering. [Mental strain and workstress. An I/O psychology approach]. Van Gorcum, Assen/Maastricht
Naumanen P (2006) The health promotion model as assessed by ageing workers. J Clin Nurs 15:219-226

Schaie KW (1994) The course of adult intellectual development. Am Psychol 49:304-313

Silverstein M (2008) Meeting the challenges of an aging workforce. Am J Ind Med 51:269-280

Sluiter JK, Van der Beek AJ, Frings-Dresen MHW (1999) The influence of work characteristics on the need for recovery and experienced health: A study on coach drivers. Ergonomics 42:573-583

Sluiter JK, Frings-Dresen MHW, Van der Beek AJ, Meijman TF (2001) The relation between work-induced neuroendocrine reactivity and recovery, subjective need for recovery, and health status. J Psychosom Res 50:29-37

Statistics Netherlands (2007). Relatief meer ouderen dan jongeren aan het werk [Relatively more old than young people work] In: Webmagazine. Available via http://www.cbs.nl/nl-NL/menu/ themas/arbeid-sociale-zekerheid/publicaties/artikelen/archief/ 2007/2007-2299-wm.htm

Statistics Netherlands (2008) Arbeidsdeelname; 15 jaar of ouder 1992-2006. In: Statline. Available via http://statline.cbs.nl/Stat Web/publication/?VW=T\&DM=SLNL\&PA=70938NED\&D1= a,!2-3,!7-10\&D2=a\&D3=0-17\&D4=3,8,13,(1-1)-1\&HD=081124$0919 \& \mathrm{HDR}=\mathrm{T}, \mathrm{G} 1 \& \mathrm{STB}=\mathrm{G} 2, \mathrm{G} 3$

Swaen GMH, Van Amelsvoort LGPM, Bültmann U, Kant IJ (2003) Fatigue as a risk factor for being injured in an occupational accident. Results from the maastricht cohort study. Occup Environ Med 60(Suppl 1):i88-i92

Van Amelsvoort LGPM, Kant IJ, Bültmann U, Swaen GMH (2003) Need for recovery after work and the subsequent risk of cardiovascular disease in a working population. Occup Environ Med 60(Suppl I):i83-i87

Van der Beek AJ, Meijman TF, Frings-Dresen MH, Kuiper JI, Kuiper S (1995) Lorry drivers' work stress evaluated by catecholamines excreted in urine. Occup Environ Med 52:464-469

Van der Hulst M, van Veldhoven M, Beckers D (2006) Overtime and need for recovery in relation to job demands and job control. $\mathrm{J}$ Occup Health 48:11-19

Van Veldhoven M (2008) Need for recovery after work. An overview of construct, measurement and research. In: Houdmont J, Leka S (eds) Occupational health psychology. European perspectives on research, education and practice, vol 3. Nottingham University Press, Nottingham

Van Veldhoven M, Broersen S (2003) Measurement quality and validity of the "need for recovery" scale. Occup Environ Med 60(Suppl 1):i3-i9 